\title{
Genetic-Dietary Regulation of Serum Paraoxonase Expression and Its Role in Atherogenesis in a Mouse Model
}

\author{
Diana M. Shih, ${ }^{\star}$ Lingjie Gu, ${ }^{\star}$ Susan Hama, ${ }^{\ddagger}$ Yu-Rong Xia, ${ }^{\star}$ Mohamad Navab,, Alan M. Fogelman, ${ }^{\ddagger}$ and Aldons J. Lusis ${ }^{\star \ddagger}$ \\ $*$ Department of Medicine, Department of Microbiology and Molecular Genetics, and Molecular Biology Institute; and ${ }^{\ddagger}$ Department of \\ Medicine, Division of Cardiology, School of Medicine, University of California Los Angeles, Los Angeles, California 90095
}

\begin{abstract}
In an effort to identify genetic factors contributing to atherogenesis, we have studied inbred strains of mice that are susceptible $(\mathrm{C57BL} / 6 \mathrm{~J})$ and resistant $(\mathrm{C} 3 \mathrm{H} / \mathrm{HeJ})$ to dietinduced aortic fatty streak lesions. When maintained on a low-fat diet, HDL isolated from both strain C57BL/6J (B6) and $\mathrm{C} 3 \mathrm{H} / \mathrm{HeJ}(\mathrm{C} 3 \mathrm{H})$ mice protect against $\mathrm{LDL}$ oxidation in a coculture model of the artery wall. However, when maintained on an atherogenic diet high in fat and cholesterol, the HDL isolated from B6 mice lose the capacity to protect, whereas $\mathrm{HDL}$ from $\mathrm{C} 3 \mathrm{H}$ mice protect equally well. Associated with the loss in the ability of HDL to protect is a decrease in the activity of serum paraoxonase, a serum esterase carried on HDL that has previously been shown to protect against LDL oxidation in vitro. The levels of paraoxonase mRNA decreased in B6 mice upon challenge with the atherogenic diet but increased in $\mathrm{C} 3 \mathrm{H}$, indicating that paraoxonase production is under genetic control. In a set of recombinant inbred strains derived from the $\mathrm{B} 6$ and $\mathrm{C} 3 \mathrm{H}$ parental strains, low paraoxonase mRNA levels segregated with aortic lesion development, supporting a role for paraoxonase in atherogenesis. (J. Clin. Invest. 1996. 97: 1630-1639.) Key words: inbred strains • diet • lipoprotein oxidation • monocytes $\bullet$ high density lipoproteins
\end{abstract}

\section{Introduction}

Inbred strains of mice differ in susceptibility to atherogenesis, providing a model system for studies of the genetic factors contributing to the disease (1). Genetic crosses between inbred strains $\mathrm{C} 57 \mathrm{BL} / 6 \mathrm{~J}(\mathrm{~B} 6)$ and $\mathrm{C} 3 \mathrm{H} / \mathrm{HeJ}(\mathrm{C} 3 \mathrm{H})$ suggested that a major gene determines aortic fatty streak development in response to a high-fat, high-cholesterol "atherogenic" diet (2). The large nongenetic variability of lesion development, however, has made precise mapping of this gene, designated Ath-1, difficult, and the identity of the gene is unknown. Because the oxidative modification of lipoproteins which accumulate in tissues in response to an atherogenic diet is thought to contribute

Address correspondence to Dr. Aldons J. Lusis, Department of Medicine, Division of Cardiology, 47-123 CHS, University of California Los Angeles, Los Angeles, CA 90095-1679. Phone: 310-825-1359; FAX: 310-794-7345; E-mail: lusislab@medicine.medsch.ucla.edu

Received for publication 6 July 1995 and accepted in revised form 10 January 1996.

J. Clin. Invest.

(C) The American Society for Clinical Investigation, Inc.

0021-9738/96/04/1630/10 \$2.00

Volume 97, Number 7, April 1996, 1630-1639 to atherogenesis $(3,4)$, we have examined these inbred strains for possible difference(s) relating to lipid oxidation. The "susceptible" strain B6 was found to exhibit dramatic induction of a variety of inflammatory genes in liver and other tissues in response to the diet whereas the "resistant" strain $\mathrm{C} 3 \mathrm{H}$ exhibited little or no induction (5). These genes included macrophagecolony stimulating factor, monocyte chemoattractant protein-1, members of the serum amyloid A (SAA) family, heme oxygenase, and glutathion transferase mu. Moreover, the activity of an nuclear factor(NF) ${ }^{1}-\kappa B$-like transcription factor was dramatically increased in $\mathrm{B} 6$ mice but not $\mathrm{C} 3 \mathrm{H}$ mice in response to the diet. Precisely this set of genes was induced in mice when injected with mildly oxidized low density lipoproteins (LDL) (6), and some of these genes have been shown to be dramatically elevated in atherosclerotic lesions $(7,8)$. Also, the levels of conjugated diene, a marker for lipid oxidation, were significantly elevated in livers of $\mathrm{B} 6$ mice as compared to $\mathrm{C} 3 \mathrm{H}$ mice even though the total lipid content was not significantly different between the two strains (5). These results suggest that the difference in atherogenesis susceptibility between the strains involves processes contributing to lipid oxidation or inflammatory gene activation in response to lipid oxidation.

Recent studies have suggested that high density lipoproteins (HDL) protect against atherogenesis in part by inhibiting the oxidative modification of LDL (9). The precise mechanisms are unclear, but HDL contain enzymes capable of destroying biologically active phospholipids in oxidatively modified LDL. These enzymes include platelet-activating factor acetylhydrolase $(10,11)$ and serum paraoxonase $(12)$. We now show that HDL isolated from both $\mathrm{B} 6$ and $\mathrm{C} 3 \mathrm{H}$ mice on a chow diet dramatically inhibit inflammatory gene expression and monocyte transmigration resulting from LDL oxidation in a coculture model of the artery wall. However, when challenged with the atherogenic diet, the HDL from susceptible B6 mice lose this protective ability whereas $\mathrm{HDL}$ from $\mathrm{C} 3 \mathrm{H}$ mice retain it. Associated with this loss of protection in HDL from B6 mice was a decrease in paraoxonase activity; HDL from $\mathrm{C} 3 \mathrm{H}$ mice, on the other hand, showed no decrease in paraoxonase activity. We further show that paraoxonase expression is regulated at the level of mRNA and that paraoxonase expression segregates with aortic lesion susceptibility in a set of recombinant inbred strains derived from parental strains B6 and $\mathrm{C} 3 \mathrm{H}$. Thus, our data indicate that the antiinflammatory properties of HDL underlie, in part, the genetic susceptibility to atherogenesis in the mouse model. They also suggest that paraoxonase expression may contribute importantly to the ability of HDL to protect against the disease.

1. Abbreviations used in this paper: NF, nuclear factor; RI, recombinant inbred. 


\section{Methods}

Mice and diets. Mice were purchased from the Jackson Laboratory (Bar Harbor, ME). All animals were female, 4-6 mo of age, at the time of the experiments. The control (chow) diet was Purina Chow (Ralston-Purina Co., St. Louis, MO) containing 4\% fat. The atherogenic diet was obtained from Teklad, Madison, WI (TD 90221) and contained $15.75 \%$ fat, $1.25 \%$ cholesterol, and $0.5 \%$ sodium cholate. Blood samples were collected from mice after 12 and $15 \mathrm{wk}$ on the diets using heparin $(2.5 \mathrm{U} / \mathrm{ml}$ blood $)$ as the anticoagulant. Lipoproteins were isolated by ultracentrifugation according to established procedures (13). HDL were isolated in the absence of EDTA to avoid inactivation of paraoxonase (14). Plasma HDL cholesterol levels were determined as described previously (15). In the experiments described, lipoprotein concentrations are expressed according to their protein content. The characterization of isolated HDL fractions from mouse plasma has previously been reported $(16,17)$.

Monocyte transmigration assay. Cocultures of human aortic endothelial cells and smooth muscle cells were treated with freshly isolated human LDL at $350 \mu \mathrm{g} / \mathrm{ml}$ in the absence or presence of various test compounds for 18-24 h. The culture supernatants, containing oxidatively modified LDL, were subsequently transferred to untreated cocultures and were incubated for an additional 18-24 h $(9,18)$. Monocytes were labeled with the fluorescent probe DiI (1,1'-dioctadecyl-3,3,3',3'-tetramethyl-indo-carbocyanine perchlorate) at $4^{\circ} \mathrm{C}$ for $10 \mathrm{~min}$ and washed. The cell pellet was resuspended in medium 199 at the desired monocyte density. At the end of the second 18-24 h treatment of cocultures, labeled monocytes were added to cocultures at $2.5 \times 10^{5}$ cells $/ \mathrm{cm}^{2}$ and incubated for $60 \mathrm{~min}$ at $37^{\circ} \mathrm{C}$. The medium containing nonadherent cells was then removed, and the cell layers were washed at $37^{\circ} \mathrm{C}$ to remove the loosely adherent cells on top of the endothelial monolayer. The cocultures were fixed and mounted, and subendothelial monocytes were enumerated under a magnification of 625 .

Arylesterase/paraoxonase activity assays. HDL samples were assayed for arylesterase activity using $1.0 \mathrm{mM}$ phenylacetate as substrate (14). The cuvette contained $1.0 \mathrm{mM}$ phenylacetate in $20 \mathrm{mM}$ Tris/ $\mathrm{HCl}, \mathrm{pH}$ 8.0. The reaction was initiated by the addition of the lipoprotein sample, and the increase in the absorbance at $270 \mathrm{~nm}$ was recorded over a 90 -s period. Blanks were included to correct for the spontaneous hydrolysis of phenylacetate. Enzymatic activity was calculated from the molar extinction coefficient $1,310 \mathrm{M}^{-1} \mathrm{~cm}^{-1}$. A unit of arylesterase activity is defined as $1 \mu \mathrm{mol}$ phenylacetate hydrolyzed per min under the above assay conditions (14). Identical results were obtained using paraoxon as substrate and determining the absorbance at $405 \mathrm{~nm}$ (14).

Cloning of mouse serum paraoxonase cDNA. A 44-nucleotide long oligonucleotide (designated PON384) complementary to a region of the human serum paraoxonase cDNA sequence from nucleotides 341 to 384 of the published sequence (19) was designed to screen a mouse cDNA library. This region is $100 \%$ conserved between the cDNAs of human and rabbit serum paraoxonase (19). The sequence of PON384 is: 5'-ATTATCTTCATCTGTGAATGTGCTAATCCCATGAGGGTTAAATG-3'. A mouse liver cDNA library in the Lambda ZAP vector (Stratagene, San Diego, CA) was screened using a 5'-end labeled PON384 probe. Hybridization was carried out in $6 \times$ SSC $(0.9$ $\mathrm{M}$ sodium chloride, $0.09 \mathrm{M}$ sodium citrate, $\mathrm{pH} 7.0$ ), $5 \times$ Denhardt's solution, $0.5 \%$ SDS, and $100 \mu \mathrm{g} / \mathrm{ml}$ denatured and sheared salmon sperm DNA, at $42^{\circ} \mathrm{C}$ overnight. After washing in $6 \times$ SSC, $0.1 \%$ SDS at $50^{\circ} \mathrm{C}$, positive clones were visualized by autoradiography. Secondary and tertiary screenings were subsequently performed to isolate individual cDNA clones, and an in vivo excision protocol was used to excise the pBluescript vector containing the cDNA insert from the original Lambda phage vector according to the manufacturer's instructions.

Two of the cDNA clones containing the longest inserts were then sequenced. The sequencing reactions were performed using the DyeDeoxy Terminator Cycle Sequencing Kit in an Applied Biosys- tems 800 Molecular Biology Labstation (Perkin-Elmer, Applied Biosystems Division, Foster City, CA). The sequencing gels were run and analyzed using an Applied Biosystems 373 DNA sequencer (PerkinElmer, Applied Biosystems Division). The accuracy of the cDNA sequence was ensured by either obtaining both sense and antisense sequences of the same cDNA clone or sequencing the same regions of the two independent cDNA clones.

Analyses of RNA. Total RNA was isolated from various organs (20). For Northern blot analyses of RNA, $5 \mu \mathrm{g}$ of total RNA were electrophoresed through formaldehyde $1.5 \%$ agarose gels and transferred to nylon membranes. The blots were hybridized with ${ }^{32} \mathrm{P}$-labeled probes at $65^{\circ} \mathrm{C}$ overnight in a solution containing $0.5 \mathrm{M}$ sodium phosphate, $1 \mathrm{mM}$ EDTA, 1\% BSA, 7\% SDS, pH 7.0. The blots were then washed in $0.1 \times \mathrm{SSC}, 0.1 \% \mathrm{SDS}$ at $65^{\circ} \mathrm{C}$ for $30 \mathrm{~min}$. Blots were dried and autoradiography was performed. The RNA dot blot analyses were performed as previously described (21). The autoradiographs were quantitated by densitometric scanning.

Mapping of the serum paraoxonase gene to mouse chromosome 6. The mouse serum paraoxonase gene was mapped by linkage analysis in an interspecific backcross between Mus spretus and C57BL/6J with C57BL/6J as the recurrent parent (22). Linkage maps were constructed for all mouse chromosomes, with the exception of the $\mathrm{Y}$ chromosome, using previously mapped gene markers, polymorphisms identified by anonymous mouse liver cDNA clones, or microsatellite (simple sequence repeat) polymorphisms. The probe for mouse serum paraoxonase was a 1,200-bp mouse serum paraoxonase cDNA and the washing conditions were $1 \times \mathrm{SSC}, 0.1 \%$ SDS at $55^{\circ} \mathrm{C}$ for $30 \mathrm{~min}$. Microsatellite polymorphisms were typed using PCR amplification followed by separation of the radiolabeled products on acrylamide gels as described (22). Primer pairs for typing microsatellite markers were purchased from Research Genetics, Birmingham, AL.

Other procedures. Gel chromatography was performed as reported previously (16). Pooled plasma samples $(450 \mu \mathrm{l})$ obtained from five B6 mice on the chow and five animals on the atherogenic diet were subjected to FPLC, and $0.5-\mathrm{ml}$ fractions were collected and were used for determination of paraoxonase activity. SDS polyacrylamide gel electrophoresis of HDL was carried out using the standard procedures as referred to previously (16). HDL was isolated ultracentrifugally from pooled plasma obtained from five B6 mice on the chow or five animals on the atherogenic diet. $10 \mu \mathrm{g}$ HDL protein was applied to each lane of a 4-20\% gradient acrylamide gel that was subjected to electrophoresis followed by staining with Coomassie brilliant blue.

\section{Results}

Genetic control of the capacity of HDL to inhibit LDL oxidation. We have previously reported that human HDL protect against LDL oxidation in an assay in which LDL is incubated for $24 \mathrm{~h}$ in a coculture of smooth muscle cells and an overlaying monolayer of endothelial cells (9). The oxidation of LDL in the assay can be assessed by monocyte migration through endothelial cell monolayer due to the induction of monocyte adhesion and chemotactic factors by the oxidized LDL products $(9,18)$. As described above, mouse strains $\mathrm{B} 6$ and $\mathrm{C} 3 \mathrm{H}$ have been developed as models for susceptibility and resistance, respectively, to diet-induced atherosclerosis. Recent studies have shown that susceptible B6 mice, but not resistant $\mathrm{C} 3 \mathrm{H}$ mice, exhibit induction of inflammatory and oxidative stress genes as well as accumulation of oxidized lipids in response to the atherogenic diet $(5,21)$. To test whether functional differences in HDL may underlie these responses, we isolated HDL from both strains, fed either a low-fat chow diet or an atherogenic diet, and examined their ability to protect against LDL oxidation in the coculture assay. As shown in Fig. $1 A$, coincubation of LDL with HDL isolated from chow-fed 
B6 or $\mathrm{C} 3 \mathrm{H}$ mice, at a concentration of $500 \mu \mathrm{g}$ protein $/ \mathrm{ml}$, reduced monocyte transmigration activity to 57 and $60 \%$, respectively, of the activity observed in LDL alone $(P=0.04$ and 0.005 , respectively). These data indicate that mouse HDL isolated from both strains are able to inhibit the oxidation of LDL as judged by reduced monocyte transmigration activity. In fact, mouse HDL are about as potent in the ability to protect against LDL oxidation as human HDL (data not shown). HDL isolated from mice fed the atherogenic diet for $12 \mathrm{wk}$, on the other hand, exhibited striking differences. Thus, at a concentration of $500 \mu \mathrm{g}$ protein/ml, strain B6 HDL failed to protect entirely whereas strain C3H HDL protected as well as that isolated from mice fed the chow diet. Similar results were obtained when we tested HDL isolated from mice fed the atherogenic diet for $15 \mathrm{wk}$ (Fig. $1 B$ ). As shown in Fig. $1 A$ and $B$, the number of monocytes per high power field varied between experiments, but the relative values between groups remained approximately the same. A total of three separate preparations of $\mathrm{HDL}$ from $\mathrm{B} 6$ and $\mathrm{C} 3 \mathrm{H}$ mice were independently tested in the coculture assay, and in each experiment HDL from strain B6 mice showed a marked decrease in the ability to protect in animals fed the atherogenic diet, whereas HDL from $\mathrm{C} 3 \mathrm{H}$ mice were about equally protective whether isolated from animals fed either chow or the atherogenic diet (data not shown).

Genetic differences in plasma serum paraoxonase activities. Serum paraoxonase has been shown to inhibit LDL oxidation both in vitro $(23,24)$ and in a coculture system $(12)$. Furthermore, serum paraoxonase is associated entirely with HDL (25). To test whether the above genetic differences in the ability of HDL to inhibit LDL oxidation may be due in part to serum paraoxonase, the activity of the enzyme as assayed by its arylesterase and paraoxonase activities was examined in HDL of $\mathrm{B} 6$ and $\mathrm{C} 3 \mathrm{H}$ mice fed the chow and the atherogenic diets. Paraoxonase/arylesterase activity in strain $\mathrm{C} 3 \mathrm{H}$ mice was increased slightly in animals fed the atherogenic diet (Fig. 2 $A$ ), whereas there was a significant decrease in paraoxonase/ arylesterase activity in strain B6 mice fed the atherogenic diet (Fig. $2 A$ ).

One consideration in these studies is the possible loss of paraoxonase from HDL upon ultracentrifugation. To minimize such loss, we adapted the method of Gan et al. (14), which includes $1 \mathrm{mM}$ calcium ion during paraoxonase purification. Under these conditions we observed $\sim 30 \%$ loss of paraoxonase activity, but this loss was strictly proportional among the two strains and on the different diets. This was observed in the two strains and using the two diets in a total of seven separate experiments. Moreover, the levels of paraoxonase recovered in isolated HDL were proportional to those in total plasma. Also, upon gel filtration chromatography of plasma, paraoxonase activity eluted entirely with the HDL fractions (Fig. $2 \mathrm{~B}$ ). It is noteworthy that upon challenge with the atherogenic diet, the distribution of paraoxonase activity in B6 mice shifted slightly to smaller HDL fractions (Fig. 2 B). Such a shift was less discernible in $\mathrm{C} 3 \mathrm{H}$ mice (Van Lenten, B.J., personal communication).

Another enzyme associated with HDL which has the ability to protect against LDL oxidation in the coculture system is platelet-activating factor acetyl transferase $(10,11)$. Levels of this enzyme were quantitated in HDL from all groups of mice and were found to be similar (data not shown).

The protein and lipid compositions of HDL from the two
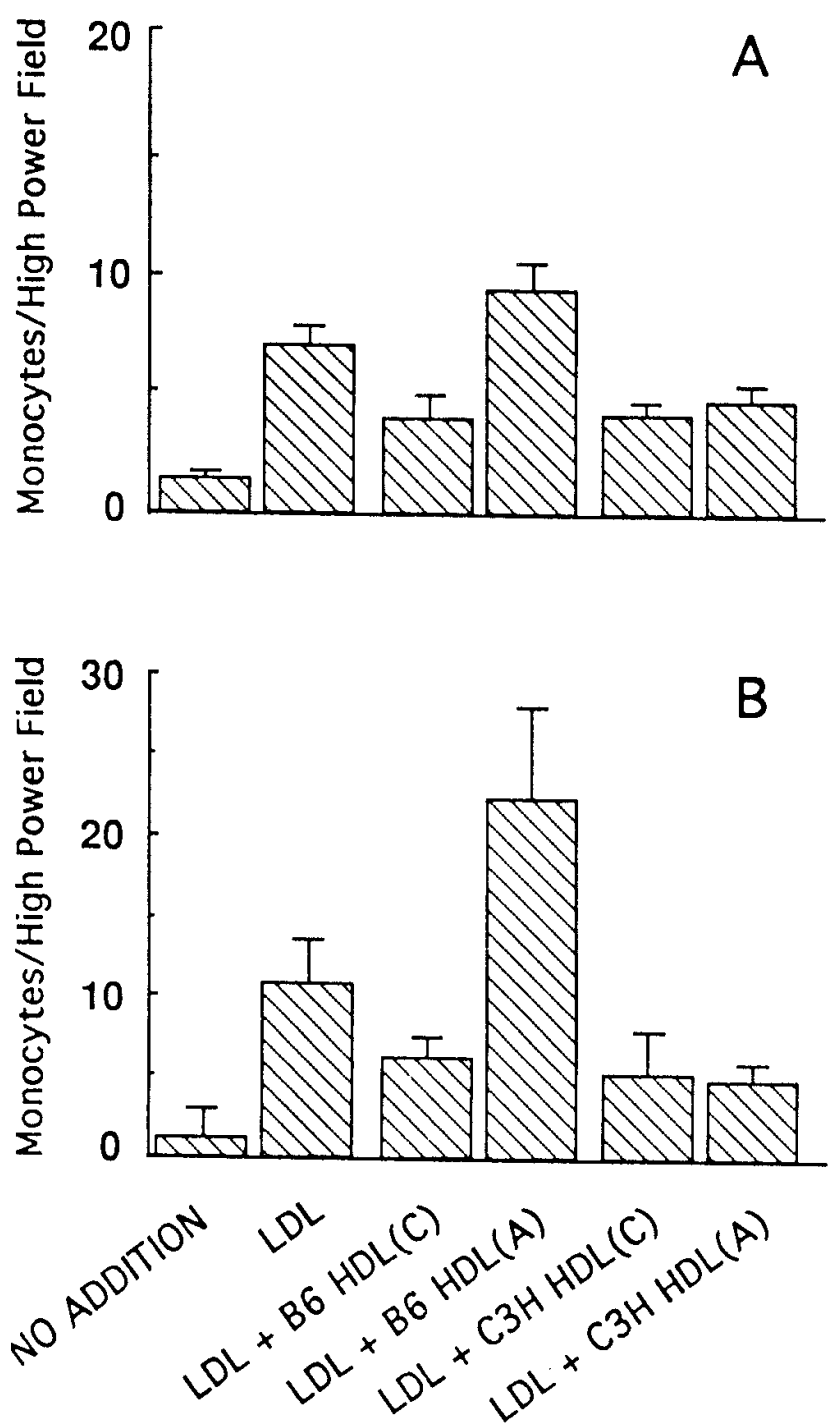

Figure 1. Protective effect of HDL from $\mathrm{B} 6$ and $\mathrm{C} 3 \mathrm{H}$ mice. Cocultures of human aortic endothelial cells and smooth muscle cells were treated with medium alone (NOADDITION), or freshly isolated LDL at $350 \mu \mathrm{g} / \mathrm{ml}(L D L)$. To some wells, the LDL was added after the addition of murine HDL $(500 \mu \mathrm{g} / \mathrm{ml})$ that were obtained from $\mathrm{C} 57 \mathrm{BL} / 6 \mathrm{~J}$ mice on chow $[L D L+B 6 H D L(C)]$ or on atherogenic diet $[L D L+B 6 H D L(A)]$, or HDL obtained from $\mathrm{C} 3 \mathrm{H} / \mathrm{HeJ}$ mice on chow $[L D L+C 3 H H D L(C)]$ or on atherogenic diet $[L D L+C 3 H$ $H D L(A)]$. After 18-24 h of incubation, conditioned medium was transferred to target cocultures. The medium was removed from the target cocultures after 18-24 h of incubation, and a suspension of DiIlabeled monocytes was added at $2.5 \times 10^{5} \mathrm{cells} / \mathrm{cm}^{2}$ to the endothelial side of the cocultures. The cultures were returned to the incubator and maintained for $60 \mathrm{~min}$. The medium was then removed, and cultures were then washed and mounted, and subendothelial monocytes were enumerated under 625 total magnification. Values shown are mean $\pm \mathrm{SD}$ of the number of monocytes in 36 fields in 12 cocultures for each treatment. $(A)$ The HDL tested were obtained from mice fed the chow or atherogenic diets for $12 \mathrm{wk}$. $(B)$ The HDL tested were obtained from mice fed the chow or atherogenic diets for $15 \mathrm{wk}$. The labels shown at the bottom of the figure are for both $A$ and $B$.

strains have previously been examined $(16,17)$, and some quantitative differences in proteins have been observed. In particular, the apolipoprotein AII content of B6 HDL, on both the chow and atherogenic diets, is less than that of $\mathrm{C} 3 \mathrm{H} \mathrm{HDL}$ 
A
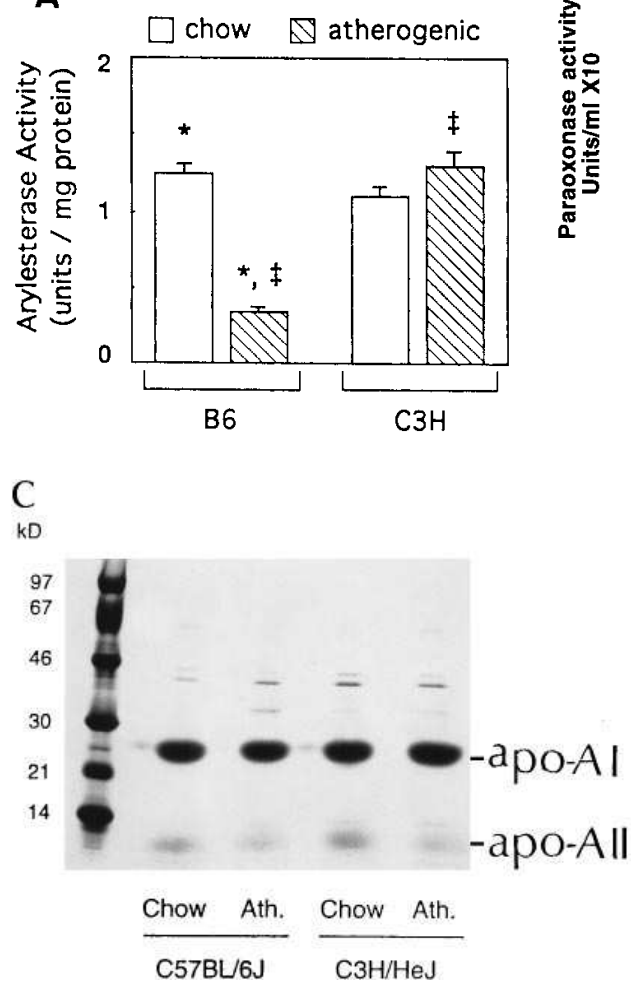

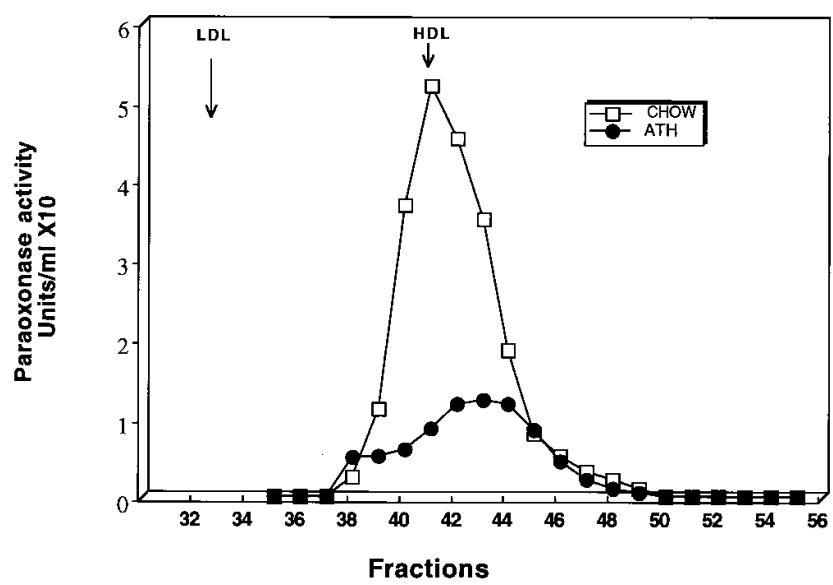

Figure 2. (A) Paraoxonase/arylesterase activity of HDL. HDL samples from mice fed the chow or atherogenic diet for $12 \mathrm{wk}$ were assayed for arylesterase activity using $1.0 \mathrm{mM}$ phenylacetate as substrate according to the procedure described in Methods. The values are mean $\pm S D$ of duplicate measurements on samples from 5 to 12 mice in each group. The following symbols indicate the significance $(P)$ values between the means of various groups as calculated by $t$ test: ${ }^{*} P<0.05,{ }^{\ddagger} P<0.01$. Similar results were obtained when HDL samples from mice fed on the diets for $15 \mathrm{wk}$ were assayed. (B) Paraoxonase activity in FPLC fractions of pooled plasma obtained from five B6 mice on the chow and five animals on the atherogenic diet. $450 \mu \mathrm{l}$ of plasma was subjected to FPLC and 0.5-ml fractions were collected. Paraoxonase activity was determined as described in Methods. $(C)$ SDS-PAGE of HDL isolated ultracentrifugally from pooled plasma (five animals per group) obtained from $\mathrm{B} 6$ mice or $\mathrm{C} 3 \mathrm{H}$ mice maintained on either the chow or the atherogenic diet. $10 \mu \mathrm{g}$ HDL protein was applied to each lane of a 4-20\% acrylamide gel that was subjected to electrophoresis by standard procedures and was stained by Coomassie brilliant blue. due to a structural polymorphism of the apo AII gene which affects its translational efficiency $(16,17)$. One-dimensional SDS-PAGE of isolated HDL from the two strains and two diets revealed the major proteins, apo AI and AII being by far the most abundant (Fig. $2 \mathrm{C}$ ). Certain quantitative differences in protein bands of unknown identity were observed (Fig. 2C), and HDL contains dozens of minor protein constituents that would not be observed by such a separation.

We attempted to examine the mass of paraoxonase in mouse plasma using available antibodies to the human enzyme, but the antibodies failed to exhibit sufficient cross reactivity (data not shown).

These changes in paraoxonase activity in $\mathrm{B} 6$ but not $\mathrm{C} 3 \mathrm{H}$ mice in response to an atherogenic diet are concordant with the changes in the ability of HDL to protect against LDL oxidation in the coculture. To examine in detail the regulation of serum paraoxonase expression, we cloned the mouse cDNA and used it to quantitate mRNA levels, as described below.

Cloning and expression of the mouse serum paraoxonase $m R N A$. An oligonucleotide (PON384) corresponding to a region of high sequence conservation between human and rabbit serum paraoxonase cDNAs was synthesized as described in Methods. Northern blot analysis of mouse liver poly A+ RNA showed that PON384 hybridized to a single mRNA species of $\sim 1,400$ nucleotides in length (data not shown), in good agreement with the sizes of human and rabbit serum paraoxonase mRNA. The oligonucleotide was used to screen a mouse liver cDNA library, and $\sim 200$ positive plaques were identified after the screening of one million plaques. Five of these were se- lected at random and plaque purified. Two clones with the longest insert sizes $(\sim 1.4 \mathrm{~kb})$ were sequenced and were in agreement with each other. The transcript contains a single, long open reading frame that would encode a polypeptide of 355 amino acids. It shows 79.1 and $81.7 \%$ identity with the human serum paraoxonase nucleotide and amino acid sequences, respectively. Fig. 3 presents the deduced amino acid sequence of mouse paraoxonase and indicates differences from the human and rabbit sequences. The mouse serum paraoxonase cDNA hybridized to a 1,400-nucleotide mRNA species that was expressed in liver (Fig. 4). A survey of tissues, including liver, heart, kidney, lung, spleen, tongue (Fig. 4), adipose tissue, brain, and testis (data not shown) indicated that serum paraoxonase expression was restricted to liver.

Regulation of serum paraoxonase $m R N A$ levels in response to an atherogenic diet. To test whether serum paraoxonase activity was controlled at the level of mRNA, we examined hepatic paraoxonase mRNA levels using Northern blot analysis and dot blot analysis. The paraoxonase mRNA levels were expressed as the optical density ratio of serum paraoxonase mRNA:18 s rRNA to correct for loading differences between samples. As shown in Fig. 5, the paraoxonase mRNA levels of B6 mice fed on atherogenic diet for 5 and 8 wk were significantly lower than the levels observed in chow-fed mice (5-wk atherogenic vs. chow, $P=0.04,8$-wk atherogenic vs. chow, $P=0.002$ ). After 5 and 8 wk of atherogenic diet feeding, the mean paraoxonase mRNA level decreased to 54 and $41 \%$ of the mean level observed in chow-fed animals, respectively. In contrast, for $\mathrm{C} 3 \mathrm{H}$ mice there was a small increase of paraoxo- 


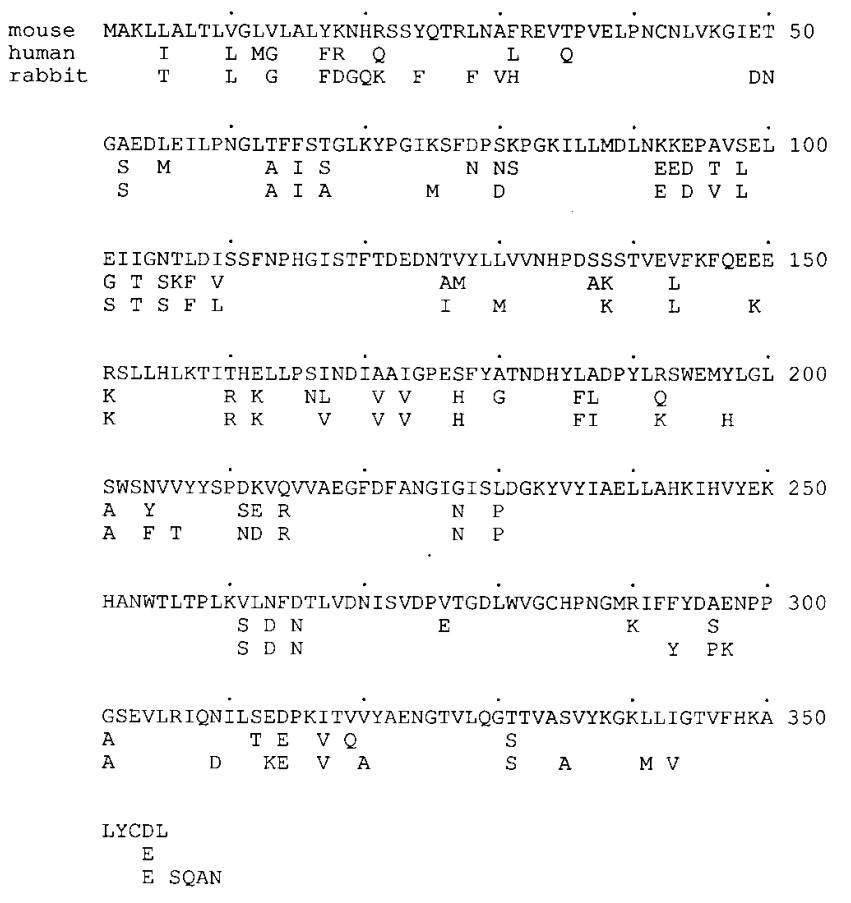

Figure 3. Deduced amino acid sequences of mouse, human, and rabbit serum paraoxonase. The complete amino acid sequence of mouse serum paraoxonase is shown. The amino acid sequences of the human and rabbit serum paraoxonase (19) are indicated at positions where they are different from the mouse sequence. The accession number for the sequence of mouse serum paraoxonase cDNA at GenBank is U32684.

nase mRNA levels after 5 and 8 wk of atherogenic diet feeding compared to chow, although the difference did not reach statistical significance (5-wk atherogenic vs. chow, $P=0.11,8$-wk atherogenic vs. chow, $P=0.09$ ). Whereas on chow diet, the B6 mice had higher levels of paraoxonase mRNA than did the $\mathrm{C} 3 \mathrm{H} / \mathrm{HeJ}$ mice $(P=0.01)$, after 8 wk of atherogenic diet feeding, the paraoxonase mRNA levels of B6 mice were $\sim 60 \%$ the levels observed in $\mathrm{C} 3 \mathrm{H}$ mice $(P=0.03)$. These results are consistent with the levels of paraoxonase activity in HDL, indicating that the atherogenic diet significantly represses paraoxonase mRNA expression in B6 mice but has little or no effect in $\mathrm{C} 3 \mathrm{H}$ mice.

Paraoxonase mRNA levels cosegregate with aortic lesion area. The finding that the susceptible strain B6 mice exhibit diminished paraoxonase expression on an atherogenic diet whereas the resistant strain $\mathrm{C} 3 \mathrm{H}$ mice maintain paraoxonase expression on the diet suggests a possible causal relationship between paraoxonase expression, inhibition of LDL oxidation by HDL, and aortic fatty streak lesion development. We used a set of recombinant inbred (RI) strains derived from the B6 and $\mathrm{C} 3 \mathrm{H}$ parental strains to address this question. RI strains are produced by crossing two parental strains and establishing a series of new homozygous inbred strains from their progeny. Each new RI strain carries a unique mixture of genes in a homozygous state derived from the two parental strains. The use of RI strains helps to determine: $(a)$ whether a single phenotype difference is determined by one or multiple gene loci; $(b)$ whether different phenotypes are determined by the same or closely linked gene loci; $(c)$ and the map location of the gene(s) that determine(s) a phenotype. Previous studies of RI

\section{Ht Kd Lv Lg Sp Tg}

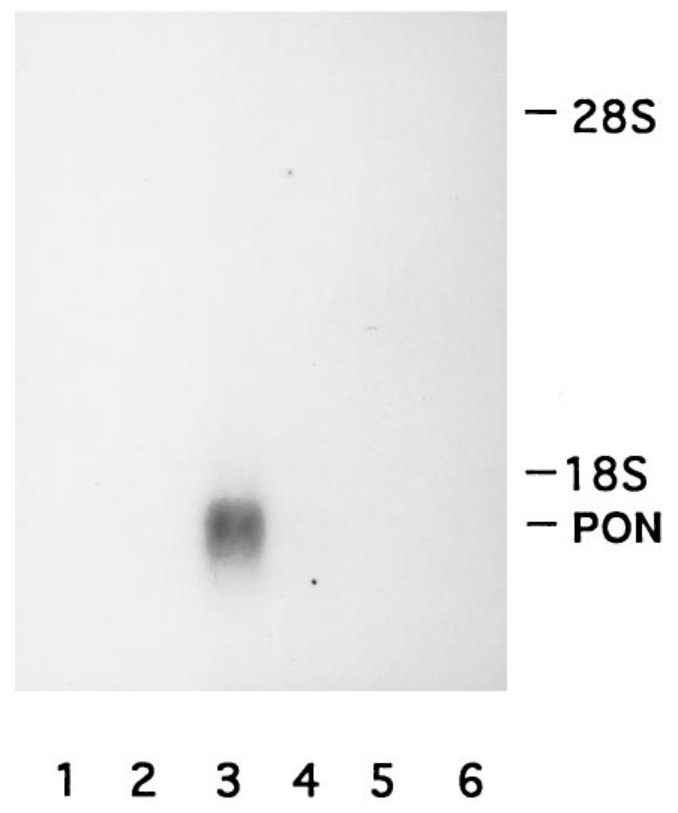

Figure 4. Tissue distribution of mouse serum paraoxonase mRNA. $5 \mu \mathrm{g}$ of RNA samples isolated from heart $(H t)$, kidney $(K d)$, liver $(L v)$, lung $(L g)$, spleen $(S p)$, and tongue $(T g)$ of a female B6 mouse were examined for expression of serum paraoxonase $(P O N)$ mRNA by Northern blot analysis. The positions of $28 \mathrm{~S}$ rRNA, $18 \mathrm{~S}$ rRNA, and PON mRNA are indicated on the right side of the figure.

strains derived from the $\mathrm{B} 6$ and $\mathrm{C} 3 \mathrm{H}$ parental strains have suggested that the difference in fatty streak development is due to one or a small number of major genes as well as minor, polygenic influences (2). Furthermore, among RI strains, aortic fatty streak lesion development segregated with high expression of inflammatory and oxidative stress genes and with accumulation of oxidized lipids (21). To test whether paraoxonase expression contributes to such responses, we examined hepatic paraoxonase mRNA levels in the set of RI strains derived from $\mathrm{B} 6$ and $\mathrm{C} 3 \mathrm{H}$ (BXH RI strains) that were maintained for $15 \mathrm{wk}$ on an atherogenic diet.

As shown in Fig. 6, the mean hepatic paraoxonase mRNA levels had a significant negative correlation with aortic fatty streak formation among these $10 \mathrm{BXH}$ RI strains. When paraoxonase mRNA levels and aortic lesion scores of individual mice were analyzed, we obtained similar results $(r=$ $-0.39, P=0.004)$. The paraoxonase mRNA levels also had a significant negative correlation with hepatic heme oxygenase mRNA levels (Fig. 6). We observed the same trend when values from individual animals were used in the analysis (log of paraoxonase vs. log of heme oxygenase, $r=-0.45, P=$ $0.0003)$. The paraoxonase mRNA levels also had a significant negative correlation with hepatic NF-кB-like activities (Fig. 6). In addition, there were negative correlations of paraoxonase mRNA levels with hepatic serum amyloid A mRNA levels, and hepatic conjugated diene levels, although they did not reach statistical significance (Fig. 6). To verify the specificity of these correlations, the paraoxonase mRNA levels and hepatic apo A-IV mRNA levels of these RI strains were analyzed by linear regression analysis. Apo A-IV was chosen because, al- 


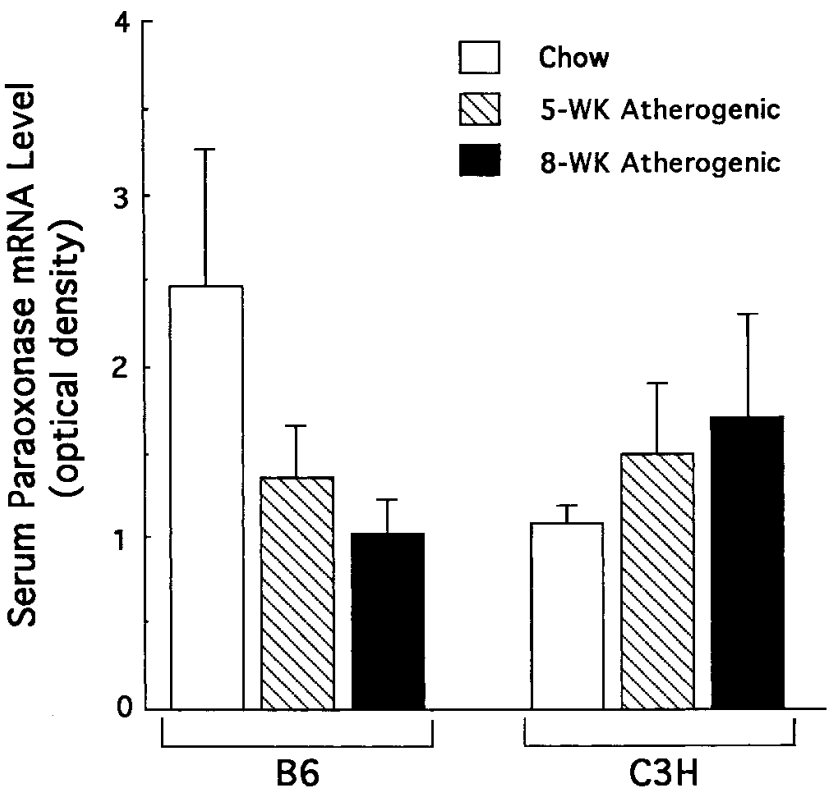

Figure 5. The effect of an atherogenic diet on serum paraoxonase mRNA levels in $\mathrm{B} 6$ and $\mathrm{C} 3 \mathrm{H}$ mice. Mice (four to seven in each group) were fed either the chow diet or the atherogenic diet for 5 and $8 \mathrm{wk}$ and were studied for the hepatic serum paraoxonase mRNA levels by Northern blot and dot blot analyses. The results of densitometry scans of a dot blot analysis are shown in the figure as the ratio of densitometry units of the serum paraoxonase mRNA to that of $18 \mathrm{~S}$ rRNA (mean \pm SD). Similar results were obtained from Northern blot analyses.

though it is responsive to a high-fat diet, apo A-IV expression is not responsive to oxidized LDL (5). As expected, there was no correlation between these two phenotypes (Fig. 6). Our results demonstrated that, upon challenge of atherogenic diet, mice that had lower paraoxonase mRNA levels tended to have more aortic fatty streak formation, more oxidative stress, and more inflammatory gene induction. On the other hand, mice that had higher paraoxonase mRNA levels tended to have less aortic fatty streak formation, less oxidative stress, and less inflammatory gene induction.

Previous studies of healthy individuals in human populations have shown a positive correlation between plasma serum paraoxonase activity/protein level and HDL level (25-27). To determine whether serum paraoxonase gene is regulated coordinately with HDL levels among the $10 \mathrm{BXH}$ RI strains of mice fed on atherogenic diet, we examined the paraoxonase mRNA levels and HDL levels of individual mice and performed regression analysis. As shown in Fig. 7, there was a very significant positive correlation between hepatic serum paraoxonase mRNA levels and plasma HDL levels in these animals $(r=0.53, P=0.0001)$, suggesting that the synthesis of serum paraoxonase is coordinately regulated with plasma HDL levels or that paraoxonase expression influences HDL levels.

Genetic control of serum paraoxonase expression is not mediated by genetic variation at the serum paraoxonase gene locus. The striking difference between $\mathrm{B} 6$ mice and $\mathrm{C} 3 \mathrm{H}$ mice in paraoxonase expression could be due either to genetic variations in the serum paraoxonase gene which influence dietary responsiveness or to genetic variations in pathways acting to control paraoxonase mRNA levels in trans. To distinguish these possibilities, we mapped the paraoxonase gene and tested whether it cosegregates with paraoxonase mRNA levels in the BXH set of RI strains.

The mouse serum paraoxonase gene was mapped by linkage analysis in an interspecific backcross between Mus spretus and $\mathrm{C} 57 \mathrm{BL} / 6 \mathrm{~J}$, with $\mathrm{C} 57 \mathrm{BL} / 6 \mathrm{~J}$ as the recurrent parent (22). Restriction fragment length variants (RFLVs) between the parental strains were identified by Southern hybridization analysis. A survey of several restriction enzymes revealed a HindIII RFLV for the serum paraoxonase gene. B6 mice exhibited hybridizing fragments of 14.5, 7.0, and $3.7 \mathrm{~kb}$, whereas Mus spretus mice exhibited hybridizing fragments of 14.5, 9.2, and 5.0 $\mathrm{kb}$. The segregation patterns of the serum paraoxonase gene locus were compared with the segregation patterns of over 350 typed genetic markers that span most of the mouse genome among the backcross animals (22). Linkage was observed with several chromosome 6 markers, including D6Mit1 and D6Mit48. The data for the linkage between the serum paraoxonase gene (designated Pon) and the nearest markers are presented in Table I. The results indicate the following order on chromosome 6: centromere-Pon-1.7 $\pm 1.0 \mathrm{cM}-$ D6Mit1-3.3 $\pm 1.3 \mathrm{cM}-\mathrm{D} 6 \mathrm{Mit} 48$. This region of mouse chromosome 6 is syntenic with a region of human chromosome 7 to which the human paraoxonase gene has been mapped (28).

In the BXH set of RI strains, the serum paraoxonase gene locus on chromosome 6 exhibited no evidence of linkage with paraoxonase mRNA levels (ANOVA analysis, $P=0.32$, calculated using the linked marker D6Mit1) or the other traits examined (data not shown). Previous studies using HDL-cholesterol levels as a marker for atherogenesis had suggested distal chromosome 1 as the likely location for the Ath-1 gene (2), but markers on mouse chromosome 1 exhibited only weak evidence of linkage with paraoxonase mRNA levels or the other traits studied (data not shown). Although paraoxonase mRNA levels tended to segregate with HDL-cholesterol levels among the set of RI strains, other genetic factors, including the apo AII gene on distal chromosome 1, also clearly contribute to HDL cholesterol levels in these strains $(15,29)$. We tested for possible linkage of PON mRNA levels with genetic markers previously typed among the RI strains. Some apparent linkages were observed, but because of the large number of comparisons made, the level of significance was not sufficient to establish linkage (data not shown).

\section{Discussion}

Our results provide support for the concept that HDL particles are functionally heterogeneous with respect to their ability to protect against atherosclerosis, and they indicate that this functional heterogeneity is influenced by genetic-dietary interactions. Thus, when susceptible B6 mice are challenged with an atherogenic diet, their HDL lose the ability to protect against the inflammatory effects of LDL oxidation in a coculture model of the artery wall, but when resistant $\mathrm{C} 3 \mathrm{H}$ are challenged with the diet, their HDL retain the ability to protect. At least one factor contributing to the protective ability of HDL appears to be serum paraoxonase $(30,31)$, an esterase carried exclusively on a subset of HDL particles (25). When challenged with the atherogenic diet, the HDL of B6 mice exhibited a significantly decreased level of paraoxonase activity whereas the $\mathrm{HDL}$ of $\mathrm{C} 3 \mathrm{H}$ mice showed a small increase. This change in paraoxonase activity was reflected almost exactly in 

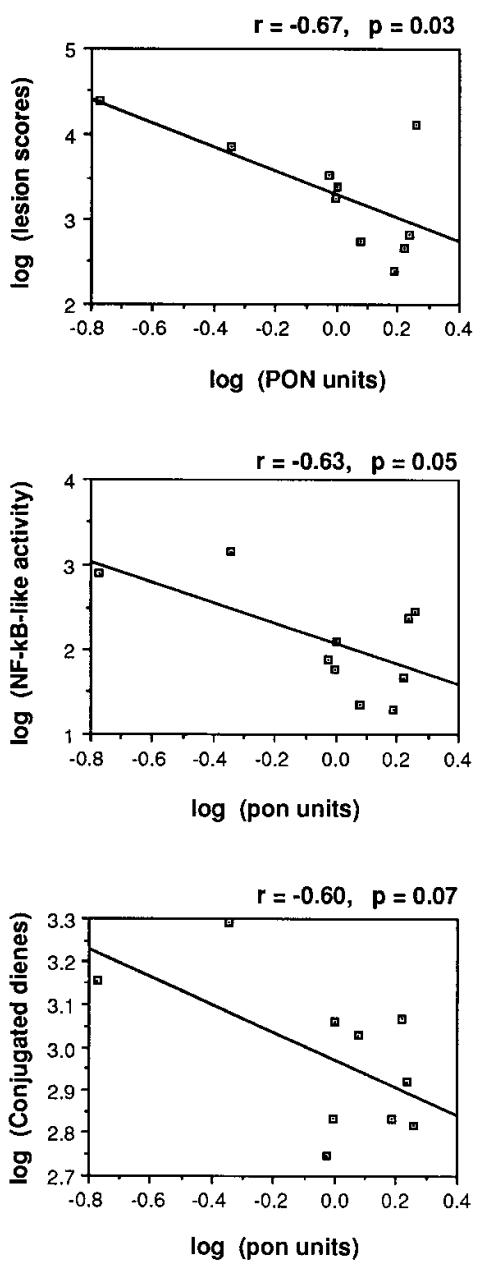
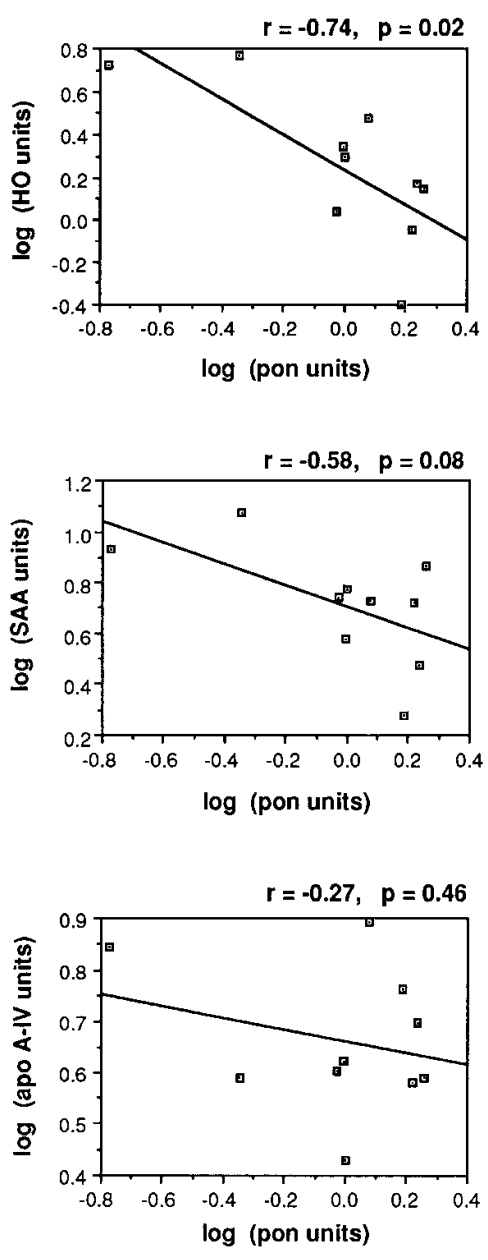

Figure 6. Negative correlation of hepatic serum paraoxonase mRNA levels with aortic lesion scores, hepatic heme oxygenase $(H O)$ mRNA levels, and hepatic activated NF- $\mathrm{KB}$-like factors. After $15 \mathrm{wk}$ on atherogenic diet, $\mathrm{BXH}$ recombinant inbred strains (three to nine animals in each group) were assessed for hepatic serum paraoxonase $(P O N)$ mRNA levels by dot blot analysis followed by densitometry scan, and the results were expressed as the ratio of densitometry units of PON mRNA to that of $18 \mathrm{~S}$ rRNA. The values shown are averaged values for each recombinant inbred strain. The averaged values for aortic lesion scores, hepatic heme oxygenase, serum amyloid A, and apo-AIV mRNA levels, hepatic conjugated diene levels, and hepatic activated NF-кB-like factors of each RI strain were previously reported (19). Correlation of paraoxonase mRNA levels with the above traits was analyzed using linear regression. The correlation coefficient $(r)$ and significance $(P)$ value of each analysis are shown on top of each panel. the levels of hepatic paraoxonase mRNA, indicating that paraoxonase gene expression is determined by both dietary and genetic factors. Significantly, paraoxonase mRNA levels were strongly correlated with aortic lesion development among RI strains derived from $\mathrm{B} 6$ and $\mathrm{C} 3 \mathrm{H}$, suggesting a causal relationship between the antiinflammatory state of HDL and atherogenesis.

An important question in our studies concerns the confounding effects of HDL levels in attempting to relate paraoxonase expression to atherosclerosis. Thus, when challenged with the atherogenic diet, B6 mice exhibit a decrease in HDLcholesterol levels whereas $\mathrm{C} 3 \mathrm{H}$ mice do not. Several lines of evidence are consistent with the conclusion that paraoxonase is at least one contributing factor to the difference in susceptibility to atherosclerosis between strains $\mathrm{B} 6$ and $\mathrm{C} 3 \mathrm{H}$. First, isolated paraoxonase inhibits LDL oxidation in the coculture model (12). Second, paraoxonase expression was significantly better correlated with atherosclerosis lesions than HDL-cholesterol concentration. Among the set of BXH RI strains, hepatic paraoxonase mRNA levels were highly correlated with aortic lesions $(r=0.39, P=0.004)$, whereas the correlation with HDL-cholesterol levels was weaker $(r=0.28, P=0.034)$. Third, among the parental strains, the levels of paraoxonase mRNA closely paralleled the levels of plasma activity, suggesting that the expression of paraoxonase is determined at the level of enzyme synthesis rather than being secondary to changes in HDL metabolism in response to the atherogenic diet. It is noteworthy that the atherogenic diet does not affect the levels of apo AI mRNA or apo AI synthesis in the B6 strain, suggesting that the decrease in HDL levels in the B6 strain is due to accelerated catabolism of HDL (17). It is unlikely that such an increase in HDL turnover would influence hepatic mRNA levels or synthesis. A fourth line of evidence comes from studies with apo AII transgenic mice which have in-

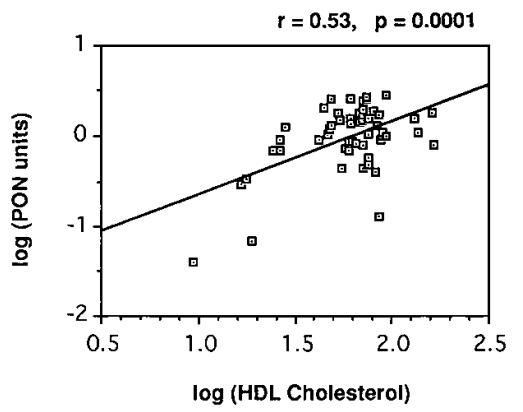

Figure 7. Correlation of hepatic serum paraoxonase $(P O N)$ mRNA levels with plasma HDL cholesterol levels in BXH RI strains. After 15 wk on atherogenic diet, $\mathrm{BXH}$ recombinant inbred strains (three to nine animals from each strain) were bled and killed after overnight fasting.

The plasma HDL cholesterol levels were determined as described in Methods. RNA samples were prepared from the livers of these mice and assessed for serum paraoxonase mRNA levels by dot blot analysis as described in Fig. 6. The PON mRNA optical density units and HDL cholesterol values of individual animals were analyzed using linear regression. The correlation coefficient $(r)$ and significance $(P)$ value are shown on top of the panel. 
Table I. Linkage of Serum Paraoxonase (Pon) Gene on Mouse Chromosome 6 in [(C57BL/6J $\times$ M. spretus $) F 1 \times$ C57BL/6J] Backcross

\begin{tabular}{cccc}
\hline & Genotype* & & \\
\hline Pon & D6Mit1 & D6Mit48 & $\begin{array}{c}\text { Number of } \\
\text { progeny }\end{array}$ \\
\hline B & B & B & 84 \\
S & S & S & 88 \\
B & B & S & 3 \\
B & S & S & 2 \\
S & S & B & \\
S & B & B & Total: \\
& & & 181
\end{tabular}

* Alleles inherited from the hybrid parent [(C57BL/6J $\times$ M. spretus $) \mathrm{F} 1]$ are designated as B or S to indicate their origin in either $\mathrm{C} 57 \mathrm{BL} / 6 \mathrm{~J}$ or $M$. spretus, respectively.

creased susceptibility to atherogenesis despite having substantially increased levels of HDL cholesterol. HDL isolated from these mice was shown to have reduced ability to protect against LDL oxidation in a coculture assay and also to have reduced paraoxonase activity (Castellani, L.W., personal communication), very much like the findings reported here. Similarly, acute-phase HDL containing high levels of serum amyloid A have reduced levels of paraoxonase activity and fail to protect against inflammatory effects of LDL oxidation in a coculture model of the artery wall (Navab, M., unpublished observation). An important future experiment will be to use transgenic animals to further test the role played by paraoxonase.

Numerous population studies have revealed a strong inverse relationship between HDL levels and the incidence of coronary artery disease (32). It has been widely assumed that this is due to the ability of HDL to function in reverse cholesterol transport, the process by which excess cholesterol is carried from peripheral tissues to liver, where it can be excreted in the bile. But there is also accumulating evidence that HDL has antiinflammatory functions which may significantly impact on atherogenesis (33-37). In particular, HDL has the capacity to inhibit LDL oxidation in vitro and to protect against the effects of LDL oxidation in tissue culture $(9,38)$. Our results implicate serum paraoxonase, a constituent of HDL, in the antiatherogenic functions of HDL. This is consistent with previous results indicating that purified paraoxonase can protect against LDL oxidation in vitro $(23,24)$ and in the artery wall coculture assay (12). Recently, it has been shown that oxidized phospholipids formed during mild oxidative modification of LDL can be hydrolyzed by paraoxonase (12). In vivo, paraoxonase could act directly on oxidized lipids in LDL, or perhaps more likely, the oxidized lipids may first be preferentially transferred to HDL. Consistent with the latter possibility is the observation that the majority of oxidized lipids present in the circulation occur on HDL (39).

Although paraoxonase expression cosegregates with aortic lesion development in our studies of RI strains derived from $\mathrm{B} 6$ and $\mathrm{C} 3 \mathrm{H}$, other genetic factors may also contribute to the differences in atherogenesis. In particular, on the atherogenic diet, HDL-cholesterol levels in B6 mice decrease about twofold whereas they are not significantly altered in $\mathrm{C} 3 \mathrm{H}$ mice; therefore, since the difference in specific activity of serum paraoxonase between $\mathrm{B} 6$ and $\mathrm{C} 3 \mathrm{H}$ mice per milligram $\mathrm{HDL}$ is $\sim 2.5$-fold, the final difference in paraoxonase activity in the two strains on the atherogenic diet is about fivefold. The fact that paraoxonase mRNA levels were correlated with HDLcholesterol levels among the BXH RI strains suggests that paraoxonase expression may influence HDL-cholesterol levels, although it is also quite possible that HDL levels and paraoxonase mRNA levels are coordinately regulated by other, unknown, mechanisms. Also, it is unlikely that paraoxonase is the only molecule on HDL responsible for its antioxidant properties. For example inhibition of paraoxonase activity by treatment of HDL with EDTA results in only a partial, not a complete, loss of HDL's ability to protect against LDL oxidation in the coculture assay (11).

The mechanisms responsible for the genetic and dietary regulation of paraoxonase expression are unknown, but, at least in mice, they act in part at the level of paraoxonase mRNA. Given the observed correlations between paraoxonase mRNA and expression of various inflammatory genes and genes responsive to oxidative stress, it seems likely that paraoxonase is part of a general inflammatory or oxidative stress response. Our results revealed that the serum paraoxonase gene does not segregate with the serum paraoxonase mRNA levels, indicating that the expression of the gene is regulated in trans. In our studies, paraoxonase expression correlated with HDL-cholesterol levels, but in certain other studies paraoxonase levels and HDL levels exhibited independent regulation. For example, in streptozotocin-treated diabetic rats, HDL levels were normal or increased whereas serum paraoxonase was reduced (40). These results are consistent with the concept that HDL particles are functionally heterogeneous with respect to atherosclerosis. This heterogeneity may underline the apparent paradox that vegetarians on low-fat diets have less coronary artery disease despite having reduced HDL and little or no change in LDL to HDL ratios. Thus, certain types of dietary modification could lower HDL levels but, at the same time, favorably affect the functional states of HDL.

Human epidemiologic and genetic studies are consistent with a role for paraoxonase in modulating both lipoprotein levels and atherosclerosis. There is a common polymorphism of serum paraoxonase in human populations, due to a single amino acid substitution, resulting in significant differences in paraoxonase activity in serum $(28,41,42)$. In one retrospective study, patients with myocardial infarction exhibited significantly lower serum paraoxonase activity than a control group (43). In case control studies, serum paraoxonase activities in individuals with hyperlipidemia or insulin-dependent diabetes mellitus exhibited decreased paraoxonase activities as compared to control groups $(44,45)$. Several population-association studies of Caucasian and Chinese populations have revealed significant positive associations between serum paraoxonase activity/protein levels and HDL cholesterol levels, and certain studies have also revealed correlations with triglyceride levels, apo AI levels, and LDL cholesterol levels $(26,27)$. Recently, a common serum paraoxonase gene polymorphism was found to be associated with levels of total cholesterol, total triglyceride, HDL cholesterol, LDL cholesterol, and apo B in a genetic isolate in Canada. It was calculated that the contribution of the genetic variation at the paraoxonase gene locus to the phenotypic variation of the above traits was significant and comparable to that of the apo E locus (46). Given these results and our present findings, additional human 
studies of the role of serum paraoxonase in atherogenesis and lipoprotein metabolism are clearly warranted.

\section{Acknowledgments}

We are grateful to Dr. Bert La Du for valuable guidance in establishing the paraoxonase and arylesterase assays, to Dr. Lawrence Castellani for help with lipid assays and lipoprotein fractionation, and to Dr. Tim Watanaskul for assistance in sequencing of mouse serum paraoxonase cDNA clones. We thank Dr. Boris Ivandic for isolation of RNA samples.

This work was supported by National Institutes of Health (NIH) grant HL-30568, state of California grants RR865 and TRDRP, and by the Laubisch Fund, UCLA. D.M. Shih was supported in part by NIH training grant 5T32DK07688-02.

\section{References}

1. Paigen, B., A. Morrow, C. Brandon, D. Mitchell, and P. Holmes. 1985. Variation in susceptibility to atherosclerosis among inbred strains of mice. Atherosclerosis. 57:65-73.

2. Paigen, B., D. Mitchell, K. Reue, R. Morrow, A.J. Lusis, and R.C. LeBoeuf. 1987. Ath-1, a gene determining atherosclerosis susceptibility and high density lipoprotein levels in mice. Proc. Natl. Acad. Sci. USA. 84:3763-3767.

3. Parthasarathy, S., D. Steinberg, and J.L. Witztum. 1992. The role of oxidized low-density lipoproteins in the pathogenesis of atherosclerosis. Annu. Rev. Med. 43:219-225.

4. Berliner, J.A., M. Navab, A.M. Fogelman, J.S. Frank, L.L. Demer, P.A. Edwards, A.D. Watson, and A.J. Lusis. 1995. Atherosclerosis: basic mechanisms, oxidation, inflammation, and genetics. Circulation. 91:2488-2496.

5. Liao, F., A. Andalibi, F.C. deBeer, A.M. Fogelman, and A.J. Lusis. 1993. Genetic control of inflammatory gene induction and NF-кB-like transcription factor activation in response to an atherogenic diet in mice. J. Clin. Invest. 91: 2572-2579.

6. Liao, F., J.A. Berliner, M. Mehrabian, M. Navab, L.L. Demer, A.J. Lusis, and A.M. Fogelman. 1991. Minimally modified low density lipoprotein is biologically active in vivo in mice. J. Clin. Invest. 87:2253-2257.

7. Rosenfeld, M.E., S. Yla-Herttuala, B.A. Lipton, V.A. Ord, J.L. Witztum, and D. Steinberg. 1992. Macrophage colony-stimulating factor mRNA and protein in atherosclerotic lesion of rabbits and humans. Am. J. Pathol. 140:291-300.

8. Yla-Herttuala, S., B.A. Lipton, M.E. Rosenfeld, T. Sarkioja, T. Yoshimura, E.J. Leonard, J.L. Witztum, and D. Steinberg. 1991. Expression of monocyte chemoattractant protein 1 in macrophage-rich areas of human and rabbit atherosclerotic lesions. Proc. Natl. Acad. Sci. USA. 88:5252-5256.

9. Navab, M., S.S. Imes, S.Y. Hama, G.P. Hough, L.A. Ross, R.W. Bork, A.J. Valente, J.A. Berliner, D.C. Drinkwater, H. Laks, and A.M. Fogelman. 1991. Monocyte transmigration induced by modification of low density lipoprotein in coculture of human aortic wall cells is due to induction of monocyte chemotactic protein 1 synthesis and is abolished by high density lipoprotein. $J$. Clin. Invest. 88:2039-2046.

10. Stafforini, D.M., G.A. Zimmerman, T.M. McIntyre, and S.M. Prescott. 1992. The platelet-activating factor acetylhydrolase from human plasma prevents oxidative modification of low-density lipoprotein. Trans. Assoc. Am. Physicians. 105:44-63.

11. Watson, A.D., M. Navab, S.Y. Hama, A. Sevanian, S.M. Prescott, D.M. Stafforini, T.M. McIntyre, B.N. Du, A.M. Fogelman, and J.A. Berliner. 1995. Effect of platelet activating factor-acetylhydrolase on the formation and action of minimally oxidized low density lipoprotein. J. Clin. Invest. 95:774-782.

12. Watson, A.D., J.A. Berliner, S.Y. Hama, B.N. La Du, K.F. Faull, A.M. Fogelman, and M. Navab. 1995. Protective effect of HDL associated paraoxanase-inhibition of the biological activity of minimally oxidized low density lipoprotein. J. Clin. Invest. 96:2882-2891.

13. Havel, R.J., H.A. Eder, and J.H. Bragdon. 1955. The distribution and chemical composition of ultracentrifugally separated lipoproteins of human serum. J. Clin. Invest. 43:1345-1353.

14. Gan, K.N., A. Smolen, H.W. Eckerson, and B.N. La Du. 1991. Purification of human serum paraoxonase/arylesterase. Evidence for one esterase catalyzing both activities. Drug Metab. Dispos. 19:100-106.

15. Warden, C.H., J.H. Qiao, L.W. Castellani, and A.J. Lusis. 1993. Atherosclerosis in transgenic mice overexpressing apolipoprotein A-II. Science (Wash. DC). 261:469-472.

16. Doolittle, M.H., R.C. LeBoeuf, C.H. Warden, L.M. Bee, and A.J. Lusis. 1990. A polymorphism affecting apolipoprotein A-II translational efficiency determines high density lipoprotein size and composition. J. Biol. Chem. 265: $16380-16388$.

17. LeBoeuf, R.C., M.H. Doolittle, A. Montcalm, D.C. Martin, K. Reue, and A.J. Lusis. 1990. Phenotypic characterization of the Ath-1 gene controlling high density lipoprotein levels and susceptibility to atherosclerosis. J. Lipid Res. 31:91-101.

18. Navab, M., G.P. Hough, L.W. Stevenson, D.C. Drinkwater, H. Laks, and A.M. Fogelman. 1988. Monocyte migration into the subendothelial space of a coculture of adult human aortic endothelial and smooth muscle cells. $J$. Clin. Invest. 82:1853-1863.

19. Hassett, C., R.J. Richter, R. Humbert, C. Chapline, J.W. Crabb, C.J. Omiecinski, and C.E. Furlong. 1991. Characterization of cDNA clones encoding rabbit and human serum paraoxonase: the mature protein retains its signal sequence. Biochemistry. 30:10141-10149.

20. Chomczynski, P., and N. Sacchi. 1987. Single step method of RNA isolation by acid guanidinium thiocyanate-phenol-chloroform extraction. Anal. Biochem. 162:156-159.

21. Liao, F., A. Andalibi, J.-H. Qiao, H. Allayee, A.M. Fogelman, and A.J. Lusis. 1994. Genetic evidence for a common pathway mediating oxidative stress, inflammatory gene induction, and aortic fatty streak formation in mice. J. Clin. Invest. 94:877-884.

22. Warden, C.H., M. Mehrabian, K.-Y. He, M.Y. Yoon, A. Diep, Y.-R Xia, P.Z. Wen, K.L. Svenson, R.S. Sparkes, and A.J. Lusis. 1993. Linkage mapping of 40 randomly isolated liver cDNA clones in the mouse. Genomics. 18: 295-307.

23. Mackness, M.I., S. Arrol, and P.N. Durrington. 1991. Paraoxonase prevents accumulation of lipoperoxides in low-density lipoprotein. FEBS Lett. 286 $152-154$.

24. Mackness, M.I., S. Arrol, C. Abbott, and P.N. Durrington. 1993. Protection of low-density lipoprotein against oxidative modification by high-density lipoprotein associated paraoxonase. Atherosclerosis. 104:129-135.

25. Blatter, M.-C., R. W. James, S. Messmer, F. Barja, and D. Pometta. 1993. Identification of a distinct human high-density lipoprotein subspecies defined by a lipoprotein-associated protein, K-45, Identity of K-45 with paraoxonase. Eur. J. Biochem. 211:871-879.

26. Saha, N., A.C. Roy, S.H. Teo, J.S.H. Tay, and S.S. Ratnam. 1991. Influence of serum paraoxonase polymorphism on serum lipids and apolipoproteins. Clin. Genet. 40:277-282.

27. Garin, M.-C.B., C. Abbott, S. Messmer, M. Mackness, P. Durrington, D. Pometta, and R.W. James. 1994. Quantitation of human serum paraoxonase by enzyme-linked immunoassay: population differences in protein concentrations. Biochem. J. 304:549-554.

28. Humbert, R., D.A. Adler, C.M. Disteche, C. Hassett, C.J. Omiecinski, and C.E. Furlong. 1993. The molecular basis of the human serum paraoxonase activity polymorphism. Nat. Genet. 3:73-76.

29. Mehrabian, M., J.-H. Qiao, R. Hyman, D. Ruddle, C. Laughton, and A.J. Lusis. 1993. Influence of the ApoA-II gene locus on HDL levels and fatty streak development in mice. Arterioscler. Thromb. 13:1-10.

30. Brealey, C.J., C.H. Walker, and B.C. Baldwin. 1980. A-esterase activities in relation to the differential toxicity of pirimiphos-methyl to birds and mammals. Pestic. Sci. 11:546-554.

31. La Du, B.N. 1992. Human serum paraoxonase/arylesterase. In Pharmacogenetics of Drug Metabolism. W. Kalow, editor. Pergamon Press, Inc., New York, 51-91.

32. Tall, A. 1990. Plasma high density lipoproteins: metabolism and relationship to atherogenesis. J. Clin. Invest. 86:379-384.

33. Eggesbo, J.B., I. Hjermann, P.K. Lund, G.B. Joo, R. Ovstebo, and P. Kierulf. 1994. LPS-induced release of IL-1 beta, IL-6, IL-8, TNF-alpha and sCD14 in whole blood and PBMC from persons with high or low levels of HDL-lipoprotein. Cytokine. 6:521-529.

34. Wurfel, M.M., S.T. Kunitake, H. Lichenstein, J.P. Kane, and S.D. Wright. 1994. Lipopolysaccharide (LPS) -binding protein is carried on lipoproteins and acts as a cofactor in the neutralization of LPS. J. Exp. Med. 180:10251035 .

35. Flegel, W.A., M.W. Baumstark, C. Weinstock, A. Berg, and H Northoff. 1993. Prevention of endotoxin induced monokine release by human low- and high-density lipoproteins and by apolipoprotein A-I. Infect. Immun. 61:5140-5146.

36. Baumberger, C., R.J. Ulevitch, and J.M. Dayer. 1991. Modulation of endotoxic activity of lipopolysaccharide by high-density lipoprotein. Pathobiology. 59:378-383.

37. Vosbeck, K., P. Tobias, H Muller, R.A. Allen, K.E. Arfors, R.J. Ulevitch, and L.A. Sklar. 1990. Priming of polymorphonuclear granulocytes by lipopolysaccharides and its complexes with lipopolysaccharide binding protein and high density lipoprotein. J. Leuk. Biol. 47:97-104.

38. Parthasarathy, S., J. Barnett, and L.G. Fong. 1990. High-density lipoprotein inhibits the oxidative modification of low-density lipoprotein. Biochim. Biophys. Acta. 1044:275-283.

39. Bowry, V.W., K.K. Stanley, and R. Stocker. 1992. High density lipoprotein is the major carrier of lipid hydroperoxides in human blood plasma from fasting donors. Proc. Natl. Acad. Sci. USA. 89:10316-10320.

40. Patel, B.N., M.I. Mackness, D.W. Harty, S. Arrol, R.P. Boot-Handford, and P.N. Durrington. 1990. Serum esterase activities and hyperlipidaemia in the streptozotocin-diabetic rat. Biochim. Biophys. Acta. 1035:113-116.

41. Playfer, J.R., L.C. Eze, M.F. Bullen, and D.A.P. Evans. 1976. Genetic polymorphism and interethnic variability of plasma paraoxonase activity. $J$. 
Med. Genet. 13:337-342.

42. Adkins, S., K.N. Gan, M. Mody, and B.N. La Du.1993. Molecular basis for the polymorphic forms of human serum paraoxonase/arylesterase: glutamine or arginine at position 191, for the respective A or B allozymes. Am. J. Hum. Genet. 52:598-608.

43. McElveen, J., M.I. Mackness, C.M. Colley, T. Peard, S. Warner, and C.H. Walker. 1986. Distribution of paraoxon hydrolytic activity in the serum of patients after myocardial infaction. Clin. Chem. 32:671-673.

44. Mackness, M.I., D. Harty, D. Bhatnagar, P.H. Winocour, S. Arrol, M.
Ishola, and P.N. Durrington. 1991. Serum paraoxonase activity in familial hypercholesterolaemia and insulin-dependent diabetes mellitus. Atherosclerosis 86:193-199.

45. Pavkovic, E., V. Simeon, E. Reiner, M. Sucic, and V. Lipovac. 1993. Serum paraoxonase and cholinesterase activities in individuals with lipid and glucose metabolism disorders. Chem. Biol. Interact. 87:179-182.

46. Hegele, R.A., J.H. Brunt, and P.W. Connelly. 1995. A polymorphism of the paraoxonase gene associated with variation in plasma lipoproteins in a genetic isolate. Arterioscler. Thromb. Vasc. Biol. 15:89-95. 